\title{
Vitamin D and susceptibility to infectious diseases: no cure for the common cold
}

\author{
Corresponding author: \\ Chris M. Florkowski \\ Canterbury Health Laboratories \\ PO Box 151 Christchurch, \\ New Zealand \\ Telephone: +64 $33640300 \times 89570$ \\ E-mail: \\ chris.florkowski@cdhb.health.nz \\ Folia Medica Copernicana 2015; \\ Volume 3, Number 4, 139-144 \\ 10.5603/FMC.2015.0008 \\ Copyright (C) 2015 Via Medica \\ ISSN 2300-5432
}

\begin{abstract}
Vitamin D influences innate immunity through up-regulation of antimicrobial peptides and adaptive immunity through modulation of both T-lymphocyte and B-lymphocyte function. Several observational studies have shown an association between low serum 25(OH)D levels and the incidence and severity of respiratory infections and also tuberculosis. Such studies, however do not fully account for confounding variables or reverse causality. The recent emergence of higher quality randomised controlled trials, however has so far not established a role for routine vitamin D supplementation in the general population for the prevention of respiratory infections. Further research, however may identify sub-groups to whom this intervention might be more appropriately targeted.

Key words: vitamin D, supplementation, infectious diseases, protective effect
\end{abstract}

Folia Medica Copernicana 2015; 3 (4): 139-144

\section{Introduction}

Vitamin $D$ is traditionally associated with bone health, although has been increasingly implicated in many other disease processes, including susceptibility to infectious diseases. There are plausible mechanisms through which vitamin D modulates immune function, including actions on both the innate and adaptive components [1]. The innate immune system is the first line of defence, which includes all mechanisms that prevent invasion without the need for memory from previous pathogen exposure. The main components of innate immunity include physical barriers (e.g. skin, tears, mucous, saliva) and non-specific inflammatory responses of tissues. The innate system prevents infection without any requirement for immunological memory from previous exposure to the pathogen [2].

Innate immunity includes the production of antimicrobial peptides, capable of killing viruses, bacteria and other organisms $[3,4]$. These peptides are produced on epithelial surfaces and within circulating white blood cells. Examples include human $\beta$-defensins 2 and 3 and cathelicidin (also known as hCAP-18 and LL-37) [4]. The peptides are produced through the effect of Toll like receptors, on the surface of macrophages and monocytes, causing cell activation when they recog- nize molecules derived from pathogens $[4,5]$. This activation results in expression of the genes that code for the vitamin $\mathrm{D}$ receptor, and for the $1 \alpha$-hydroxylase enzyme that converts the pre-hormone, $25(\mathrm{OH}) \mathrm{D}$, to the biologically active 1,25 dihydroxyvitamin $D$; which in turn activates the gene that produces cathelicidin [5]. Cathelicidin has both direct (increased membrane permeability) and indirect effects (chemotaxis of immune cells) which neutralise the pathogen. An increase in the concentration of cathelicidin in phagocytic vacuoles enhances the cells ability to kill micro-organisms [4]. LL-37, the only human cathelicidin, has been identified in white cells, breast milk, skin, lung, saliva, and colon. It is active against a wide range of microbes, including bacteria (both gram positive and gram negative), fungi and viruses [6].

The adaptive immune system is more complex than the innate system and is dependent upon the innate system for antigen presentation to which it then mounts a specific, remembered response [1]. The relationship of vitamin $D$ with the adaptive immune system is similarly more complex. Vitamin $D$ modulates both T-lymphocyte and B-lymphocyte function. Vitamin D suppresses T-helper cell proliferation and modulates their cytokine production. Cell mediated immunity is promoted and vitamin $\mathrm{D}$ has also been shown to have 
a direct effect on $B$ lymphocyte proliferation and immunoglobulin production [1].

\section{Vitamin D and tuberculosis}

The postulated mechanisms linking vitamin $D$ and cathelicidin provide a possible explanation for the link between sun exposure, vitamin $\mathrm{D}$ and tuberculosis (TB) [7]. There is increasing evidence that low body vitamin $D$ levels may increase the risk of developing TB. For example, a hospital-based case-control study found that vitamin $D$ deficiency was associated with an odds ratio of $2.9(95 \% \mathrm{Cl} 1.3-6.5)$ for having active TB [8]. A case series of London TB patients showed that $56 \%$ had undetectable plasma $25(\mathrm{OH}) \mathrm{D}$ levels $(<2.8 \mathrm{ng} / \mathrm{mL})$ [9]. Another case-control study from West Africa observed lower mean serum 25(OH)D levels in cases $(31 \mathrm{ng} / \mathrm{mL})$ compared with controls $(34 \mathrm{ng} / \mathrm{mL})$; $p<0.001$ [ [10]. Susceptibility to TB has been linked to vitamin D-receptor polymorphisms, with the presence of the Fokl $\mathrm{F}$ allele protecting against TB infection, and the Taql t allele protecting against active disease but not infection [11].

\section{Vitamin D and respiratory infection}

The association between rickets and infection has been known for several decades [12]. Many studies have reported that children with rickets commonly present to hospital with respiratory infections [13-21]. One of these observed lower serum 25(OH)D levels in cases of acute severe lower respiratory infection requiring admission to hospital compared with controls: $9.2 \mathrm{v}$. $15.2 \mathrm{ng} / \mathrm{mL}(\mathrm{p}<0.0001)$ [21].

Exposure to sunshine and UVB, which is the primary source of vitamin $D$ in humans, is also associated with respiratory infection markers [22]. Sub-erythemal courses of UV radiation, administered twice a year for three years to Russian teenage athletes, resulted in fewer respiratory viral infections, fewer days of absences and shorter duration of illness, compared with non-irradiated athletes [23].

A study from the Netherlands found that children with low sun exposure were more likely to have a cough and a runny nose, compared to children with highest sun-exposure [24]. The temporal association between seasonal changes in vitamin $\mathrm{D}$ levels and winter respiratory virus activity has led to the proposal that low vitamin $D$ levels may have a causal role in the onset of influenza epidemics $[25,26]$.

Several observational studies have reported on vitamin $\mathrm{D}$ status and respiratory infection. A case-control study from Turkey found that serum 25(OH)D levels were lower in neonatal cases of acute lower respiratory infection $(9.2 \mathrm{ng} / \mathrm{mL})$ than age-matched controls (16.4 ng/mL) [27]. A cohort study from Finland found that young male soldiers with serum $25(\mathrm{OH}) \mathrm{D}$ levels $<16 \mathrm{ng} / \mathrm{mL}$ at baseline had a $63 \%$ increased risk of absence from duty over the following 6 months due to respiratory infection compared with soldiers with levels $>16 \mathrm{ng} / \mathrm{mL}(p=0.004)$ [28]. A case-control study of children aged 1-25 months found no difference in mean serum $25(\mathrm{OH}) \mathrm{D}$ levels between cases of acute lower respiratory tract infection $(30.8 \mathrm{ng} / \mathrm{mL})$ and hospital controls $(30.8 \mathrm{ng} / \mathrm{mL})$ [29]. This observation, however is probably due to virtually all of the infants having high vitamin $D$ diets through fortified formula or supplementation. Further analysis of the US NHANES III survey showed that, after adjusting for demographic and clinical characteristics, lower $25(\mathrm{OH}) \mathrm{D}$ levels were independently associated with self-reported URI in the past few days (compared to $\geq 30 \mathrm{ng} / \mathrm{mL}$ group: OR 1.36 [95\% Cl 1.01-1.84] for $<10 \mathrm{ng} / \mathrm{mL}$ and $\mathrm{OR}$ 1.24 [95\% Cl 1.07-1.43] for 25-74 nmol/L groups) [30].

Observational studies of vitamin $D$ and respiratory infection, however are likely to be affected by confounding variables that are not fully accounted for. They are also likely to be affected by the phenomenon of reverse causality, where subjects who are 'sickly' for whatever reason are less likely to spend time outdoors exposed to sunlight. In accordance with the principles of Evidence Based Medicine, strong evidence of whether there is a true effect of vitamin $D$ on the risk of infection can really only be provided by randomised controlled trials (RCTs) of intervention. This point was reinforced in a systematic review, published in 2009 by Yamschikov et al., who identified 13 clinical trials addressing the effect of vitamin $D$ on treatment and prevention of infectious diseases in humans [31]. Considerable heterogeneity existed amongst the individual studies reviewed and it was concluded that more rigorously designed clinical trials were needed in this area.

\section{Vitamin D supplementation and respiratory infection}

Recent randomised controlled trials (RCTs) of vitamin $D$ supplementation have examined its impact on respiratory infection. A study designed to investigate bone-loss in post-menopausal African-American women found that $8 \%$ of women on 800 to $2000 \mathrm{IU}$ per day reported having cold or influenza symptoms over the 3 years follow-up compared with $25 \%$ of women on placebo $(p<0.002)$ [32]. The prevalence of URI symptoms in this study, however will have been underestimated due to the insensitive and imprecise manner in which these data were collected, although the double-blinded, 
randomised study design should have minimised reporting bias. In a sub-study of an RCT to prevent fractures with vitamin D supplementation, 3444 participants (mean age 77 years) were asked in winter if they had suffered an infection or received antibiotics during the previous week [33]. For intention-to-treat comparisons, there was a non-significant $10 \%$ reduction in the odds of reporting infection $(p=0.23)$ and $16 \%$ reduction in the odds of reporting antibiotic use $(p=0.18)$. Slightly stronger effects were observed for on-treatment per-protocol comparisons: $20 \%$ reduction in reporting infection $(p=0.06)$ and $26 \%$ reduction in reporting antibiotics $(p=0.10)$. The limitations of this study include the short outcome period of only one week, which reduced power, and its low dose of vitamin D (800 IU/day) which increased 25(OH)D levels from $15.2 \mathrm{ng} / \mathrm{mL}$ to only $24.8 \mathrm{ng} / \mathrm{mL}$, well below the 32 to $40 \mathrm{ng} / \mathrm{mL}$ range now considered to be associated with optimum adult health outcomes [34-37].

More recently, our group reported a randomized, placebo-controlled double blind clinical trial to determine the effect of vitamin D supplementation on incidence and severity of upper respiratory infections (URIs) in healthy adults [38]. In the Vitamin D and respiratory infection study (VIDARIS), 322 healthy adults (161 in each treatment group) were enrolled, who were employees of our local hospital board or university, between February 2010 and November 2011 in Christchurch, New Zealand [38]. They were allocated to monthly oral $100,000 \mathrm{IU}$ vitamin D3 after a loading dose or placebo for a total of 18 months. The primary end point was number of URI episodes. Secondary end points were duration of URI episodes, severity of URI episodes, number of days off work as a result of URI episodes, and detection of respiratory viruses in nasopharyngeal samples. The mean baseline $25(\mathrm{OH}) \mathrm{D}$ level was 29 (SD 9) ng/mL, and only five (1.6\%) participants had levels $<10 \mathrm{ng} / \mathrm{mL}$. Vitamin D supplementation resulted in an increase in serum 25(OH)D levels that was maintained at $>48 \mathrm{ng} / \mathrm{mL}$ throughout the study [38].

There were 593 URI episodes in the vitamin D group and 611 in the placebo group, with no statistically significant differences in the number of URIs per participant [mean 3.7 per person for the vitamin $D$ group, 3.8 for the placebo group; RR $0.97(95 \% \mathrm{Cl} 0.85-1.11)]$. There were also no significant differences in the number of days off work as a result of URIs [0.76 for each group; RR 1.03 (95\% Cl 0.81-1.30)], duration of symptoms per episode [mean 12 days for each group; RR 0.96 (95\% Cl 0.73-1.25)] or severity of URI episodes [38]. These findings remained unchanged when the analysis included season or baseline $25(\mathrm{OH}) \mathrm{D}$ levels. We also documented no episodes of hypercalcemia nor any adverse events attributed to vitamin D. The monthly administration of 100,000 IU vitamin D3 was therefore not found to reduce the incidence or severity of URIs in healthy, predominantly European adults with near normal vitamin D levels [38].

The strengths of the VIDARIS study include the relatively large sample size, the 18-month duration (including two winters), and the high-dose of vitamin D3 administered together with a loading dose, thus avoiding the shortcomings of previous adult studies. The dosing regimen, started during summer/autumn, resulted in sustained mean $25(\mathrm{OH})$ D levels $>48 \mathrm{ng} / \mathrm{mL}$ throughout the study period in those in the intervention arm. Other strengths are the stringent efforts to capture URI episodes and the collection of virological data. In VIDARIS, however we were unable to assess the effect of vitamin D supplementation on prevention of infection caused by individual viruses, although there were few cases of confirmed influenza among the group of partly-vaccinated participants [38].

The findings of the VIDARIS study are consistent with some but not all RCTs that were specifically designed to assess whether vitamin $D$ supplementation prevents acute respiratory infections in adults.

In a study of 162 adults, there was no benefit of vitamin $D$ supplementation in decreasing the incidence or severity of URIs during winter [39]. This study, however was of short duration (12 weeks), underpowered, used a relatively low dose of vitamin $\mathrm{D}(2,000 \mathrm{IU}$ daily $)$ without a loading dose and first administered vitamin D3 during (rather than before) winter [39].

Laaksi et al. also showed no difference in the number of days absent from duty due to respiratory tract infection in 164 soldiers randomized to vitamin D3 (400 IU daily) or placebo for 6 months over winter, although the overall proportion of participants who had no days absent from duty was lower in the vitamin $D$ group [40]. This study was also underpowered and the relatively low dose of vitamin D3 resulted in only $29 \%$ of those in the intervention group obtaining $25(\mathrm{OH}) \mathrm{D}$ levels > $32 \mathrm{ng} / \mathrm{mL}$ [40].

More recently, two studies showed differing effects of vitamin $D$ supplementation in children. In a study conducted in Mongolia, classrooms of 744 Mongolian schoolchildren were randomly assigned to different treatments in winter and analysis focused on a subset of 247 children who were assigned to daily ingestion of unfortified regular milk (control, $n=104$ ) or milk fortified with 300 IU vitamin D3 ( $n=143)$; in double-blinded fashion [41]. At baseline, the median serum 25(OH)D level was $7.0 \mathrm{ng} / \mathrm{mL}$ (interquartile range, 5 to $10 \mathrm{ng} / \mathrm{mL}$ ) [41]. At the end of the study period, the median 25(OH)D levels of children in the control versus vitamin $\mathrm{D}$ groups significantly differed (7.0 v. $19 \mathrm{ng} / \mathrm{mL})$, respectively; $p<0.001$ ) [41]. Compared to controls, children on vitamin $D$ reported significantly fewer ARIs during the study period (mean: 0.80 v. 0.45 infections, respec- 
tively; $p=0.047)$, with a rate ratio $[\mathrm{RR}]$ of $0.52(95 \% \mathrm{Cl}$ $0.31-0.89$ ) [41]. Adjusting for age, sex, and history of wheezing, vitamin $D$ continued to halve the risk of ARI (RR 0.50, 95\% Cl $770.28-0.88$ ) [41]. Similar results were found among children either below or above the median $25(\mathrm{OH}) \mathrm{D}$ level at baseline (RR 0.41 v. 0.57 , respectively; $\left.P_{\text {interaction }}=0.27\right)[41]$.

In contrast, vitamin D supplementation did not affect the incidence of first episodes of pneumonia in 1524 infants from Afghanistan, another population with a high prevalence of vitamin D deficiency [42].

In a double-blind RCT for the prevention of acute respiratory infection in older adults and their carers (ViDiFlu), the addition of intermittent bolus-dose vitamin D3 supplementation to a daily low-dose regimen did not influence risk of acute respiratory infection in older adults and their carers [43].

In another RCT from New Zealand, healthy pregnant women, from 27 weeks' gestation to birth, and their infants, from birth to age 6 months, were assigned to placebo or one of the two dosages of daily oral vitamin D3 [44]. In comparison with the placebo group (99\%), the proportion of children making any acute respiratory infection visits was smaller in the higher-dose (87\%, $p=0.004)$, but not the lower-dose vitamin D3 group (95\%, $p=0.17$ ) [44]. It was concluded that vitamin D3 supplementation during pregnancy and infancy reduces primary care visits for acute respiratory infection during early childhood [44].

In a 2X2 factorial, RCT to assess whether vitamin D3 supplementation (10,000 IU per week) versus placebo and gargling versus no gargling could prevent viral, clinical upper respiratory tract infection (URTI) in university students, 600 students were randomised into 4 treatment arms: 1) vitamin D3 and gargling, 2) placebo and gargling, 3) vitamin D3 and no gargling, and 4) placebo and no gargling [45]. Seventy participants $(23.3 \%)$ randomized to vitamin D3 reported clinical URTI compared to $80(26.7 \%)$ randomized to placebo (RR 0.79, 95\% Cl 0.61-1.03, p=0.09). Vitamin D3 treatment was associated with a significantly lower risk for laboratory confirmed URTI $(p=0.007)$ and with a significantly lower mean viral load. It was concluded that vitamin D3 is a promising intervention for the prevention of URTI [45].

In a post hoc analysis of data from pilot D-Health, an RCT in a general community setting, 644 Australian residents aged 60-84 y were randomly assigned to receive monthly doses of either placebo $(n=214)$ or $30,000(n=215)$ or $60,000(n=215)$ IU oral cholecalciferol [46]. Those participants assigned to $60,000 \mathrm{IU}$ cholecalciferol, had $28 \%$ lower risk of having antibiotics prescribed at least once than did people in the placebo group (RR 0.72; 95\% Cl 0.48-1.07, although this was not significant [46].
In a RCT, 180 pregnant women were randomised at 27 weeks gestation to either no vitamin D, 800 IU ergocalciferol daily until delivery or single oral bolus of 200,000 IU cholecalciferol [47]. No difference was found between supplemented and control groups in risk of wheeze in the offspring and there was also no significant difference in atopy, eczema risk or lung function between the groups [47].

As an adjunct to a multi-centre, RCT of colorectal adenoma chemoprevention, it was tested whether $1000 \mathrm{IU} /$ day vitamin $\mathrm{D}(3)$ supplementation reduced winter episodes and duration of URTI and its composite syndromes [48]. The RCT included 2259 participants aged 45-75 and in otherwise good health, apart from history of colorectal adenoma, who were were randomized to vitamin $\mathrm{D}(3)$ (1000 IU/day), calcium (1200 mg/day), both, or placebo [48]. Participants had a baseline serum $25(\mathrm{OH}) \mathrm{D}$ level $\geq 12 \mathrm{ng} / \mathrm{mL}$. It was found that supplementation did not significantly reduce winter episodes of URTI (RR 0.93, 95\% Cl 0.79-1.09) including colds [48].

The effect of adjunctive vitamin $D$ for treatment of active tuberculosis was investigated in India in an RCT [49]. Of the 247 participants, 121 were assigned to vitamin D intervention (four doses of $2.5 \mathrm{mg}$ at weeks 0,2 , 4 , and 6) and 126 to the placebo group. Median time to sputum culture conversion in the vitamin $D$ group was 43.0 days $(95 \% \mathrm{Cl} 33 \cdot 3-52 \cdot 8)$ v. $42 \cdot 0$ days $(33 \cdot 9-50 \cdot 1)$ in the placebo group. Vitamin D supplementation therefore did not reduce time to sputum culture conversion [49].

Other significant trials are in progress and expect to report at a later date. For example, in North America, the DO IT Trial is a pragmatic RCT of vitamin D Outcomes and Interventions in Toddlers [50]. It is planned to recruit 750 healthy children $1-5$ years of age over 4 successive winters who will be randomized to either 'standard dose' or 'high dose' oral supplemental vitamin D for a minimum of 4 months. The aim is to identify whether vitamin $\mathrm{D}$ supplementation can reduce wintertime viral URTIs and asthma exacerbations [50].

In a recent trial of vitamin $D$ supplementation to reduce exacerbations of chronic obstructive pulmonary disease, vitamin $D$ supplementation significantly reduced exacerbations only in patients with baseline $25(\mathrm{OH})$ D levels $<10 \mathrm{ng} / \mathrm{mL}$ [51].

In a randomized controlled trial in Japanese school children, set up to assess the effect of vitamin D supplementation on "doctor diagnosed influenza," there was a statistically significant reduction in laboratory-confirmed influenza A infection (RR 0.58, $p=0.04$ ) [52].

The findings of the various RCTs undertaken in this context are therefore mixed, although the VIDARIS study stands out for its methodological rigour, as indicated above [38]. A valid discussion point is whether the VIDARIS results would have been different if participants 
had been given vitamin $D$ 3,300 IU daily, as compared to 100,000 IU monthly. Different outcomes have been documented for trials of 4-monthly versus annual dosing regimens of vitamin $D$ supplementation for risk of fractures $[53,54]$. Several mechanisms have been proposed to explain how various dosing regimens may have different effects on immune function [55]. However, it is purely speculative at this stage as to whether some conditions (e.g. infections) require a smaller steady dose of vitamin D supplementation for benefit. Another plausible hypothesis is that genetic variation in vitamin $D$ metabolism or signalling may modify the anti-infective effects of vitamin D. Vitamin $D$ receptor polymorphisms, for example have been linked to both susceptibility to tuberculosis [56] and the response to vitamin D supplements in patients with tuberculosis [57].

\section{Conclusions}

Vitamin D may influence immune function through actions on both the innate and adaptive systems. Observational studies have shown an association between low 25(OH)D levels and the incidence and severity of respiratory infections, although do not fully account for confounding variables or reverse causality. The emergence of higher quality randomised controlled trials, such as the New Zealand based VIDARIS study, however has so far not conclusively established a role for routine vitamin D supplementation in otherwise healthy adults for prevention of respiratory infections. Further intervention studies, however should focus on other sub-groups, including children with lower baseline vitamin D levels.

\section{References}

1. Hewison M. Vitamin D and immune function: autocrine, endocrine or paracrine? Scand J Clin Lab Invest Suppl 2012; 243: 92-102.

2. White JH. Vitamin D Signaling, Infectious Diseases, and Regulation of Innate Immunity. Infect Immun 2008; 76: 3837-3843.

3. Ganz T. Defensins: antimicrobial peptides of innate immunity. Nat Rev Immunol 2003; 3: 710-720.

4. Zasloff M. Fighting infections with vitamin D. Nat Med 2006; 12 388-390.

5. Liu PT, Stenger S, Li H, Wenzel L et al. Toll-like receptor triggering of a vitamin D-mediated human antimicrobial response. Science 2006; 311: 1770-1173.

6. Dürr UHN, Sudheendra US, Ramamoorthy A. LL-37, the only human member of the cathelicidin family of antimicrobial peptides. Biochim Biophys Acta (BBA) - Biomemb 2006; 1758: 1408-1425.

7. Martineau AR, Honecker FU, Wilkinson RJ, Griffiths CJ. Vitamin D in the treatment of pulmonary tuberculosis. J Steroid Biochem Molec Biol 2007; 103: 793-798.

8. Wilkinson RJ, Llewelyn M, Toossi Z et al. Influence of vitamin D deficiency and vitamin $D$ receptor polymorphisms on tuberculosis among Gujarati Asians in west London: a case-control study. Lancet 2000; 355: 618-621.

9. Ustianowski A, Shaffer R, Collin S, Wilkinson RJ, Davidson RN. Prevalence and associations of vitamin $D$ deficiency in foreign-born persons with tuberculosis in London. J Infect 2005; 50: 432-437.
10. Wejse C, Olesen R, Rabna P et al. Serum 25-hydroxyvitamin D in a West African population of tuberculosis patients and unmatched healthy controls. Am J Clin Nutr 2007; 86: 1376-1383.

11. Wilbur AK, Salter Kubatko L, Hurtado AM, Hill KR, Stone AC. Vitamin $D$ receptor gene polymorphisms and susceptibility to $M$. tuberculosis in Native Paraguayans. Tuberculosis 2007; 87: 329-337.

12. Stroder J, Kasal P. Phagocytosis in vitamin D deficient rickets. Klin Wochenschr 1970; 48: 383-384.

13. Banajeh SM, Al-Sunbali NN, Al-Sanahani SH. Clinical characteristics and outcome of children aged under 5 years hospitalized with severe pneumonia in Yemen. Annal Trop Paediat 1997; 17: 321.

14. Beser $\mathrm{E}$, Cakmakci T. Factors affecting the morbidity of vitamin D deficiency rickets and primary protection. East Afr Med J 1994; 71: 358-362.

15. El-Radhi AS, Majeed M, Mansor N, Ibrahim M. High incidence of rickets in children with wheezy bronchitis in a developing country. J Roy Soc Med 1982; 75: 884-887.

16. Mariam TW, Sterky G. Severe rickets in infancy and childhood in Ethiopia. J Pediatr 1973; 82: 876-878.

17. Muhe L, Lulseged S, Mason KE, Simoes EAF. Case-control study of the role of nutritional rickets in the risk of developing pneumonia in Ethiopian children. Lancet 1997; 349: 1801-1804.

18. Najada AS, Habashneh MS, Khader M. The Frequency of Nutritional Rickets among Hospitalized Infants and its Relation to Respiratory Diseases. J Trop Pediatr 2004; 50: 364-368.

19. Patwari A, Nabi G, Nadroo AM, Singh D, Manhas RS. Pulmonary changes in rickets in children. Ind Pediatr 1979; 16: 413-415.

20. Siddiqui TS, Rai MI. Presentation and predisposing factors of nutritional rickets in children of Hazara Division. J Ayub Med Coll Abbottabad 2005; 17: 29-32

21. Wayse V, Yousafzai A, Mogale K, Filteau S. Association of subclinical vitamin $\mathrm{D}$ deficiency with severe acute lower respiratory infection in Indian children under 5 y. Eur J Clin Nutr 2004; 58: 563-567.

22. Holick MF. Resurrection of vitamin D deficiency and rickets. J Clin Invest 2006; 116: 2062-2072.

23. Gigineishvili GR, Il'in NI, Suzdal'nitskii RS, Levando VA. The use of UV irradiation to correct the immune system and decrease morbidity in athletes. Vopr Kurortol Fizioter Lech Fiz Kult 1990; 3: 30-33.

24. Termorshuizen F, Wijga A, Gerritsen J, Neijens HJ, van Loveren H. Exposure to solar ultraviolet radiation and respiratory tract symptoms in 1-year-old children. Photodermatol Photoimmunol Photomed 2004; 20: 270-271

25. Cannell J, Zasloff M, Garland C, Scragg R, Giovannucci E. On the epidemiology of influenza. Virol J 2008; 5: 29.

26. Cannell JJ, Vieth R, Umhau JC et al. Epidemic influenza and vitamin D. Epidemiol Infect 2006; 134: 1129-1140.

27. Karatekin G, Kaya A, Salihoğlu Ö, Balci H, Nuhoğlu A. Association of subclinical vitamin $D$ deficiency in newborns with acute lower respiratory infection and their mothers. Eur J Clin Nutr 2009; 63: 473-477.

28. Laaksi I, Ruohola J-P, Tuohimaa P et al. An association of serum vitamin D concentrations $<40 \mathrm{nmol} / \mathrm{L}$ with acute respiratory tract infection in young Finnish men. Am J Clin Nutr 2007; 86: 714-717.

29. Roth DE, Jones AB, Prosser C, Robinson JL, Vohra S. Vitamin D status is not associated with the risk of hospitalization for acute bronchiolitis in early childhood. Eur J Clin Nutr 2009; 63: 297-299.

30. Ginde AA, Mansbach JM, Camargo CA. Association between serum 25-hydroxyvitamin $\mathrm{D}$ level and upper respiratory tract infections in the Third National Health and Nutrition Examination Survey. Arch Intern Med 2009; 169: 384-390

31. Yamschikov AV, Desai NS, Blumberg HM, Ziegler TR, Tangpricha V. Vitamin $D$ for prevention and treatment of infectious diseases: a systematic review of randomised, controlled, clinical trials. Endocr Pract 2009; 15: 438-449.

32. Li-Ng M, Aloia JF, Pollack S et al. A randomized controlled trial of vitamin D3 supplementation for the prevention of symptomatic upper respiratory tract infections. Epidemiol Infect. 2009; 137: 1396-1404.

33. Avenell A, Cook JA, MacLennan GS, MacPherson GC Vitamin D supplementation to prevent infections: a sub-study of a randomised placebo-controlled trial in older people (RECORD trial, ISRCTN 51647438). Age Ageing 2007; 36: 574-577.

34. Bischoff-Ferrari HA, Giovannucci E, Willett WC, Dietrich T, Dawson-Hughes B. Estimation of optimal serum concentrations of 25-hydroxyvitamin D for multiple health outcomes. Am J Clin Nutr 2006; 84: 18-28.

35. Black PN, Scragg R. Relationship Between Serum 25-hydroxyvitamin $\mathrm{D}$ and pulmonary function in the Third National Health and Nutrition Examination Survey. Chest 2005; 128: 3792-3798.

36. Scragg R, Sowers M, Bell C. Serum 25-hydroxyvitamin D, diabetes, and ethnicity in the Third National Health and Nutrition Examination Survey. Diabetes Care 2004; 27: 2813-2818. 
37. Scragg R, Sowers M, Bell C. Serum 25-hydroxyvitamin D, ethnicity, and blood pressure in the Third National Health and Nutrition Examination Survey. Am J Hypertens 2007; 20: 713-719.

38. Murdoch DR, Slow S, Chambers ST et al. Effect of vitamin D3 supplementation on upper respiratory tract infections in healthy adults. The VIDARIS Randomized Controlled TrialJAMA 2012; 308 1333-1339.

39. Li-Ng M, Aloia JF, Pollack $\mathrm{S}$ et al. A randomized controlled trial of vitamin D3 supplementation for the prevention of symptomatic upper respiratory tract infections. Epidemiol Infect 2009; 137: 1396-1404.

40. Laaksi I, Ruohola J-P, Mattila V, Auvinen A, Ylikomi T, Pihlajamäki. Vitamin D Supplementation for the prevention of acute respiratory trac infection: A randomized, double-blinded trial among young finnish men. J Infect Dis 2010; 202: 809-814

41. Camargo CA, Ganmaa D, Frazier AL et al. Randomized trial of vitamin $D$ supplementation and risk of acute respiratory infection in Mongolia. Pediatrics 2012; 130: e561-e567.

42. Manaseki-Holland S, Maroof Z et al. Effect on the incidence of pneumonia of vitamin $D$ supplementation by quarterly bolus dose to infants in Kabul: a randomised controlled superiority trial. Lance 2012; 379: 1419-1427.

43. Martineau AR, Hanifa Y, Witt KD et al. Double-blind randomised controlled trial of vitamin D3 supplementation for the prevention of acute respiratory infection in older adults and their carers (ViDiFlu). Thorax 2015; 70: 953-960.

44. Grant CC, Kaur S, Waymouth E et al. Reduced primary care respiratory infection visits following pregnancy and infancy vitamin D supplementation: a randomised controlled trial. Acta Paediatr 2015; 104: 396-404

45. Goodall EC, Granados AC, Luinstra K et al. Vitamin D3 and gargling for the prevention of upper respiratory tract infections: a randomized controlled trial. BMC Infect Dis 2014; 19: 273

46. Tran B, Armstrong BK, Ebeling PR et al. Effect of vitamin D supplementation on antibiotic use: a randomized controlled trial. Am J Clin Nutr 2014; 99: 156-161.
47. Goldring ST, Griffiths CJ, Martineau AR et al. Prenatal vitamin d supplementation and child respiratory health: a randomised controlled trial. PLoS One 2013; 24: e66627.

48. Rees JR, Hendricks K, Barry EL et al. Vitamin D3 supplementation and upper respiratory tract infections in a randomized, controlled trial. Clin Infect Dis 2013; 57: 1384-1392

49. Daley $\mathrm{P}$, Jagannathan $\mathrm{V}$, John $\mathrm{KR}$ et al. Adjunctive vitamin $\mathrm{D}$ for treatment of active tuberculosis in India: a randomised, double-blind, placebo-controlled trial. Lancet Infect Dis 2015; 15: 528-534.

50. Maguire JL, Birken CS, Loeb MB et al. DO IT Trial: vitamin D Outcomes and Interventions in Toddlers - a TARGet Kids! randomized controlled trial. BMC Pediatr 2014; 8: 37.

51. Lehouck A, Mathieu $C$, Carremans $C$ et al. High doses of vitamin D to reduce exacerbations in chronic obstructive pulmonary disease. Ann Int Med 2012; 156:105-114.

52. Urashima M, Segawa T, Okazaki M, Kurihara M, Wada Y, Ida H. Randomized trial of vitamin D supplementation to prevent seasonal influenza A in schoolchildren. Am J Clin Nutr 2010; 91: 1255-1260.

53. Sanders KM, Stuart AL, Williamson EJ et al. Annual high-dose oral vitamin D and falls and fractures in older women. JAMA 2010; 303: 1815-1822.

54. Trivedi DP, Doll R, Khaw KT. Effect of four monthly oral vitamin D3 (cholecalciferol) supplementation on fractures and mortality in men and women living in the community: randomised double blind controlled trial. BMJ 2003; 326: 469

55. Martineau AR. Bolus-dose vitamin $D$ and prevention of childhood pneumonia. Lancet 2012; 379: 1373-1375.

56. Wilbur AK, Salter Kubatko L, Hurtado AM, Hill KR, Stone AC. Vitamin $D$ receptor gene polymorphisms and susceptibility $M$. tuberculosis in Native Paraguayans. Tuberculosis 2007; 87: 329-337.

57. Martineau AR, Timms PM, Bothamley GH et al. High-dose vitamin D3 during intensive-phase antimicrobial treatment of pulmonary tuberculosis: a double-blind randomised controlled trial. Lancet 2011; 377: $242-250$ 